\title{
Discussion on the Flexible Manufacturing and Operation Strategy Model for a Machine Tool Component Company in Taiwan
}

\author{
Jui-Lung Chen ${ }^{1}, \&$ Shih-Hsuan Yang ${ }^{1}$ \\ ${ }^{1}$ Department of Business Administration, National Chin-Yi University of Technology, Taiwan, R.O.C \\ Correspondence: Jui-Lung Chen, Department of Business Administration, National Chin-Yi University of \\ Technology, No.57, Sec. 2, Zhongshan Rd., Taiping Dist., Taichung 41170, Taiwan, R.O.C.
}

Received: July 26, 2021

Accepted: August 12, $2021 \quad$ Online Published: August 17, 2021

doi:10.5539/ibr.v14n10p1

URL: https://doi.org/10.5539/ibr.v14n10p1

\begin{abstract}
Recently, many manufacturing industries have been facing challenges such as rising material costs, smallvolume and large-variety products, shortened production cycles, increased labor costs and longer after-sales service times, which is a very tough challenge for most small and medium-sized component manufacturing suppliers. In addition to the current hot topics in the manufacturing industry - Smart Manufacturing (Industry 4.0) and lean production management, if small and medium-sized enterprises are not able to adjust the pace of manufacturing timely and find a suitable production model, they will soon be overwhelmed by the torrent of the era of speed and accuracy. In the face of the dramatic changes in the industry structure, the company can deploy the global expansion of overseas customers in advance, and adjust to apply and implement a flexible manufacturing model system through the introduction of the Industrial Internet of Things and flexible manufacturing production management. In order to meet the market needs, the manufacturing industry is gradually oriented towards customized production and the rapid development of new products. To meet such stringent requirements, flexible manufacturing becomes one of the necessary ways for enterprises to consider their development models. Therefore, the efficiency and reliability of work can be improved through the Industrial Internet of Things that facilitates machine-to-machine communication, cloud-based big data and learning and imitations of smart robots. This study is an in-depth study of a company that is currently in the process of digital transformation, collecting relevant information and reviewing the analysis to find a suitable smart manufacturing solution for the company and to explore the impact of the COVID-19 pandemic on the strategic development of the company. The findings can provide a significant reference for homotypic companies in the development of their business strategies.
\end{abstract}

Keywords: flexible manufacturing, smart manufacturing, industry 4.0, lean production, industrial internet of things, big data

\section{Introduction}

The early manufacturing industry was labor-intensive, and machinery equipment was mainly manual and traditional specialized machines. In order to meet the market trend of diversifying customer requirements, a production system that was suitable for a wide range of products and in small quantities was developed. The Flexible Manufacturing System (FMS) is an engineering system that allows for flexible and automated production for predictable or unpredictable changes in industrial manufacturing activities. It can adapt to the rapid changes in the product market, engaging in small-volume and large-variety production to meet the different needs of the market (Groover, 2001). The use of a highly FMS to enhance operations and organization can cope with the high frequency of product modifications that are inevitable in a customer-oriented market (Wong et al., 1999). The main focus is on the processing or production of machinery for a wide range of applications, including production processes, machine assembly, production application machines and some production automation activities. These manufacturing systems can be used to achieve different levels of production flexibility, which is entirely related to the components of the system. FMSs are often used in production plants for the small-volume and large-variety production and highly variable combinations of components and products. Therefore, the main feature of the FMS is that when the production process requires a change of product configuration, it is not necessary to change the production machinery frequently, and the production configuration can be modified by computerized industrial control systems to meet the rapidly changing requirements of the market for products, as well as the needs of customers for small- 
volume and large-variety products (Groover, 2001). In the face of rapid changes in the structure of market activities, how can small and medium-sized enterprises use the production model of FMSs to develop products that meet the increasing demand of customers for small-volume and large-variety products, to meet the market demand for innovative production.

Machine tools are the "mother of machines", and components are the foundation of machine tools. In our daily lives, everything we touch, large or small, may be directly or indirectly produced by machine tools. A good and precise machine tool relies on the assembly of a large number of precise components. In recent years, the highly competitive nature of the traditional manufacturing industry and the increasing diversity of customer-oriented demand have forced small and medium-sized enterprises to change their production patterns to meet the urgent needs of customers. The market orientation of products has gradually changed from mass production to smallvolume and large-variety production, with low-technology and low precision changing to high-technology and high precision, and the customization demand has increased significantly (Lee, 2017). For many small and mediumsized component manufacturing suppliers in Taiwan, this is a very difficult challenge to change production models. In addition to the hot topic-smart manufacturing and lean production management, if small and medium-sized enterprises are not able to adjust the production pace and find a suitable model, they will soon be weeded out by the era pursuing speed and accuracy (Ramadan and Salah, 2019). For general small and medium-sized enterprises, the ability to receive one-off orders and carry out uninterrupted production in large quantities is the most economical production mode that can reduce production costs and increase production efficiency, as their combination and variability of products are very simple; the opposite is true for small-volume and large-variety production. For general enterprises, they need to take not only the production cost, product quality, customer delivery and pre-sales, in-sales and after-sales customer service needs, but also these invisible service costs into consideration of the production cost. As a result of the increased complexity of the manufacturing process, the uncertainties that need to be considered significantly increase, such as the production efficiency and the scrap rate caused by improper processing...These drastic transformations in the production model will test the production conditions of the enterprises again and again. For strong enterprises, they can combine mass production with small-volume and large-variety production; for the average ones, they can choose one or the other model to survive; for unsound enterprises, they may be eliminated or even close down. This change in the industrial structure of the production model is an opportunity for the traditional manufacturing industry to transform, and the flexible application of the production model is also a test of the technical and management strategies of SME operators. Only those who can improve their capabilities in the process of dramatic changes, and mitigate the huge impact and commitment, can truly achieve sustainable business operation.

The world's manufacturing industry is now facing digital transformation, and the challenge of the fourth industrial revolution are coming. Today's standardized production is not sufficiently efficient or productive, and production lines cannot be used flexibly, resulting in over-production of finished goods, for example, overstocking and hoarding, which are gradually being replaced. In the current trend of customer-oriented development, the only way for manufacturing companies to enter into Industry 4.0 is to integrate the Internet and machinery to efficiently improve competitiveness, productivity and reduce product costs, and stand out in the competitive market. Although the investment in the Industrial Internet of Things (IIoT) and FMS will not immediately bring significant results and differences, and the industry has to invest a lot of capital, personnel, equipment, resources and technology, the manufacturing industry is facing a serious challenge that it must face up to the industrial upgrading and transformation instead of a choice. The subject of this study is a traditional small and medium-sized component manufacturing supplier that has been in business for more than 30 years since its establishment. In the face of the dramatic changes in the industry structure, the company not only can deploy its global expansion of overseas customers but also can make timely adjustments. It can move forward with its efforts, and stand up to the downturn environment and stand out among peers by using the IIoT and flexible manufacturing management, and implementing the FMS. This study explores how small and mediumsized enterprises in the machine tool manufacturing and precision nut industry cluster can build competitive advantages in the highly competitive and harsh environment through analysis of the machine tool manufacturing and precision nut industry, as well as the application of the competitive advantages and strategic development of the company, and to plan strategic management directions and adjust strategic approaches in response to the dramatic and rapid changes in the future.

\section{Literature Review}

\subsection{Introduction to the Case Company}

The case company (Y) was originally established in 1989 as a traditional OME of nut components and established machine tool processors for precision component turning and OEM for customers. In addition to the 
existing local market in Taiwan, it is now selling high-quality products to over 30 countries including Germany, Switzerland, Japan, Italy, United States, China and other countries around the world. The case company understands the importance and urgency of product quality to customers, so it pays close attention to each production process and detail. In addition, the case company has not only invested in the importation of high-end complex production equipment but has also spared no expense in establishing the industry's first "precision nut R\&D and testing laboratory", in the hope of achieving zero defects and high-quality products to meet customer needs. The main product of the company is precision nuts, which are different from the commonly known screw nuts in terms of specifications and applications, as well as the high-quality requirements, and are used in markets where high precision is required, such as spindles and ball screws in the components industry. As the market for precision nuts is becoming saturated and the scope for expansion is limited, and the industry structure has changed slightly, overseas companies are actively looking for suppliers in Taiwan to corporate closely based on the consideration of procurement costs. Therefore, the company has engaged in customized precision component manufacturing.

\subsection{Flexible Manufacturing}

FMS is a product design system that meets the modern highly variable requirements by combining components to meet various needs, and by allowing the changes of output and specific limits at will. In other words, multiple workhorses can be linked together into a common interconnected group by the same controlled production manufacturing system and transport system, which can carry out automated production and process different workpieces without any machine adjustments (Inman, 1991; Groover, 2001). In general, a FMS must have the following features: (1) the ability to identify and recognize the production process for different number of working days, (2) the ability to quickly switch operational commands, (3) the ability to quickly switch machine settings (Luggen, 1991). There are thousands of different combinations of arrangements of FMSs for companies with different needs. However, no matter how different the arrangement is, it is necessary to have six major functions such as material control, production management, quality management, monitoring management, tool management and automatic operation. To make the most of the FMS, hierarchical management and decentralized methods are often used (Maleki, 1991, Wang et al., 2016).

In general, the development and maturity of FMSs are mainly due to the variability of the market and the uncertainty of the real environment, and the competitiveness of a company depends on its ability to respond flexibly to changes in the market according to its existing capabilities (Gerwin, 1993). Under different conditions, there are different types of flexible manufacturing, which can be roughly divided into external and internal flexibility. External flexibility can be subdivided into flexibility in quantity and type in response to market changes; internal flexibility is process flexibility, e.g., the ability to change production schedules or work plans at any time in the event of a sudden equipment failure, and flexibility in material handling, e.g., the ability to deliver materials to the on-site process unit in real-time, and the ability to allow for random changes in quantity. Internal flexibility is also important in terms of machine troubleshooting or the ability to adjust the production schedules during a machine breakdown (D'Souza and Williams, 2000). If flexibility in flexible manufacturing is considered, it is related to the ability to communicate, the interdependence of departments, and the flexibility and capability of suppliers (Lau, 1999), with the management of the supply chain and the re-establishment of manufacturing processes being the key factors driving flexibility in flexible manufacturing (Oke, 2005).

\subsection{Lean Production}

Lean production is focusing on the real needs and requirements of the customer and eliminating unnecessary waste in the production process; it adopts a "pull" production mode rather than a mass production based on longterm forecasting (or "push" production) (Womack and Jones, 2003). Feld (2001) divided the lean production mode into four key stages, distinguishing as the critical audits and realistic assessments of lean production, gaps in current conditions, design of future conditions, and the design and planning of lean projects for implementation decisions. Feld (2001) identified the key factors for successful implementation of lean manufacturing as decision motivation, persistence, leadership style and direction control. The core concept of lean production is to focus on the customers' needs, to eliminate unnecessary waste, to reduce production costs, to adopt a "pull" production drive, and to harness the potential of all employees to continuously improve and build a diverse, low-volume and fluent production system (Krafcik, 1988). The key concept of the Lean Production System was a production management and operation system developed by Toyota Motor Corp in Japan to reduce production costs, shorten delivery cycles and improve product quality, and to develop a production model that includes operation philosophy, production organization, logistics control, quality management, cost control, inventory management, site management and site improvement. Nowadays, many companies are following the example of Toyota Motor Corp and have introduced the TPS concept into their lean 
production system, which has increased productivity. In this way, the lean production system can be introduced to the small and medium-sized enterprises in Taiwan's manufacturing industry, and in the case of the smallvolume and large-variety hand tool industry, lean production management can be implemented to gradually develop the production procedure, identify unnecessary waste, and gradually improve the production procedure to achieve the ultimate goal of shortening the product delivery time and passing strict quality detection (Lee, 2017).

\subsection{Smart Manufacturing - Industry 4.0}

Most of the world's advanced countries are now facing globalized economies, aging populations, climate change, urbanization and other challenges, resulting in global competition, rising material costs, product diversification but shortened production cycles, increased labor costs and after-sales service for the manufacturing industry. Industry 4.0, also known as Smart Manufacturing, was first introduced in 2011 by Germany at Hannover Messe and has influenced manufacturing industries worldwide. Before the development of smart manufacturing, there was already a mature manufacturing execution system (MES) that allowed the manufacturing industry to schedule production cycles, track the production process and achieve basic management through the IoT, and then it developed into the IIoT (Bartodziej, 2017). In the past, traditional factories were often unable to predict or immediately detect abnormalities in equipment, and it often took a lot of time to check and troubleshoot the equipment, or perhaps to procure components, which would lead to no productivity, time and labor costs, and have an impact on delivery and customers' sense of trust. In this case, the IIoT can be used to connect all manufacturing-related elements, monitor them in real-time and transfer the captured information back to the system for optimization, allowing managers to remotely monitor the status of equipment, such as activation and spectaculars, even when they are not on site. In addition, previous data collection can be used to accurately predict the equipment or its configuration tools, such as when a tool needs to be replaced or when a spindle needs maintenance (Lai, 2017). Industry 4.0 will revolutionize design, manufacturing, operations, and product service and production systems. Industry 4.0 is made up of big data, cloud technology, automation, system integration, the IoT, cybersecurity, cascading manufacturing, augmented reality, and simulation, all of which are integral. The IIoT plays a linking role, allowing systems to automatically exchange information, trigger actions and conduct self-monitoring, and is an important bridge for linking these nine key technologies together to achieve a smart factory (Rüßmann et al., 2016).

\subsection{Industrial Internet of Things}

The new industrial automation drove by the IIoT is leading to a new concept of "Industry 4.0" and different fields of technology, which can further solve the upgrading problems faced by the global manufacturing industry. With the accumulated experience in automation and artificial intelligence study as the basis, Germany is no longer confined to the restrictive thinking and framework of "automation will completely replace labor", but instead places more emphasis on "human-machine interface collaboration". For the manufacturing industry, they need to use big data generated by the IIoT, combining with artificial intelligence (AI) and the Artificial Intelligence and the Internet of Things (AIoT) to achieve digital twins of human-machine interface and realize the integration of real and virtual smart manufacturing. Industry 4.0 has led to a new wave of Smart Manufacturing, which uses the IIoT and AI to achieve intelligent production plants of AIoT, thus providing sensors to collect data and optimize the performance of production, or solve problems in advance of anomalies and increase productivity and efficiency. It is a distributed control system with the IIoT, AI, as well as AIoT $(\mathrm{AI}+\mathrm{IIoT}=\mathrm{AIoT})$ to create Digital Twins for human-machine collaboration and to achieve Cyber Physical Systems for smart manufacturing (Wu, 2019).

\section{Methodology}

\subsection{Case Study Method}

This study was a case study of a machine tool component company in Taiwan with a flexible manufacturing strategy. The main data sources can be divided into two different types, primary data and secondary data (Cooper, 1995). Primary data are collected by the researcher from a single side of the subject. Secondary data are collected from journals, books and magazines, databases, etc. (Wu, 2015). This study first focused on the small and medium-sized enterprises in the case study, and obtained important information from various sources such as the case company's website, market observation post system, journals, newspapers or magazines, and papers by Ph.D.'s, which was how the secondary data for this study was obtained. Based on the collection of secondary data, an open-ended topic was developed as the interview outline, and the researcher obtained primary data through the field observation and one-on-one interviews with relevant members, thus making the data source more adequate and comprehensive, and facilitating the development of the study and the analysis of the findings 
and suggestions of the relevant topic.

Because the qualitative research has always been tentative and dynamic on the study content and conclusion and it can gain an in-depth understanding of the existing small and medium-sized enterprises in the production of machine tool components in central Taiwan, and considering the company that introduces a flexible manufacturing strategy and its flexibility and the ability to process production-related issues, an in-depth and semi-structured interview with unit managers who are inextricable with operation is conducted. Pan (2003) argued that in qualitative research interviews, there was an inseparable partnership between the researcher and the interviewee and that the purpose of the dialogue was truly achieved through verbal communication and emotional exchange. Semi-structured interviews are also known as "Semi-standardized Interviews" or "Guided Interviews", and a form of data collection that is intermediate between structured and unstructured interviews. In the pre-structured interview, the researcher must first develop an outline based on the research questions and purposes, which serves as a guideline for the subsequent interviews (Pan, 2003). However, during the interview process, the interviewer is not required to follow the outline in its exact order, but to adapt the questions to the actual situation (Dyer and Sánchez, 1998). The semistructured interview is flexible in the sense that the interviewees in different departments have different perspectives on the questions. Therefore, this study adopts the semi-structured interview for its flexibility in question adjustment during the interview. According to Yin (2009), for the case study, the research strategy is divided into five main categories: experiment, surveys, archival analysis, history and case study. The selection of the appropriate strategy has to be assessed in the light of the actual situation, and is usually determined by: (1) the type of research question; (2) the degree of control the researcher has over the event; and (3) whether the event is a current or historical phenomenon. The case study is a research strategy, and choosing a single case study needs to use various methods, such as actual observation, personal interviews, research surveys, pilot experiments. Relevant methods can help to collect important information about the complete machine tool components operated by small and medium-sized enterprises in central Taiwan, and about the enterprises' introduction of flexible manufacturing strategies, to analyze the facts, to explain the reasons for the introduction, and to solve or improve the important methods. Through the case study, the information generated can be more accurate in the introduction process of flexible manufacturing of the machine tool component manufacturing industry. Yin (2009) argued that the case study was well suited to interview specificity or pioneering issues; Benbasat et al. (1987) argued that the case study was well suitable when theory and research were at an early stage of development, and in contrast, the experience of the researcher was particularly important and crucial to the decision. This study adopted a case study method to conduct more in-depth analysis and research by using actual field observations, personal interviews, data collection and surveys. The case study was mainly used to explore the activities and contexts in which a case was developed in a particular context, and to facilitate the understanding of the complexities and uniqueness. This study conducted a "semi-structured interview" through an in-deep interview, without any pre-determined forms, questionnaires, or standard operating procedures of a certain direction. Through a free conversation between the interviewer and the interviewee, the interviewer was free to ask any questions, and the interviewee was free to express his views, no matter what the topic was. This was a way to get a deeper insight into what the interviewees think, what their future development blueprint was, and what their solutions to problems were (Wen and Yang, 2000).

\subsection{Interviewees and Outline}

In qualitative research, there are three important stages in the analysis procedure and rule of the interview method. The first stage is the collection and consolidation of relevant literature and case studies before the scheduled interview. The second stage is to gradually guide the interviewee to respond with more specific and relevant statements through the main question during the real interview process. The third stage is the compilation and discussion of the data after the interview, in which the interviewees and the interviewees validate the data together to achieve completeness and consistency between the data and the statements. In addition, the important interview process in qualitative research consists of three stages: pre-interview, ininterview, and post-interview. At the pre-interview stage, when compiling the main content of the interview, it is required to develop better and systematic questions focusing on research purposes and literature discussion, including the depth and breadth. The core questions must be asked progressively to capture the background, decisions and personal feelings of the interviewees concerning their own or their company's major events. This study aimed to achieve a sense of comfort and security for interviewees through the usual pre-scheduled appointments and their decisions of the interview location and time, and to guide the interviewees gradually through the mutual conversation to elaborate on the most real and personal thoughts, and to confirm the content of the answers and the consistency of the questions, which ensured the understanding of interviewees on the meaning of the question. The interviewee in this study was the most large-scale small and medium-sized enterprise in machine tool component manufacturing in central Taiwan, as well as the senior vice president and 
middle and senior managers of the executive management who worked closely with the management. The list of interviewees and their basic information are shown in Table 1.

Table 1. List of Company and People Interviewed

\begin{tabular}{cccc}
\hline \multirow{2}{*}{ Interviewee code } & \multicolumn{3}{c}{ Interviewee and year of experience } \\
\cline { 2 - 4 } & Job title & Department & Year of experience \\
\hline Interviewee A & Executive Vice President & Company operation & 24 \\
\hline Interviewee B & Manager & $\begin{array}{c}\text { Production and } \\
\text { Management Department }\end{array}$ & 22 \\
\hline Interviewee C & Manager & Processing Department & 17 \\
\hline
\end{tabular}

This study focused on the factors of the introduction of flexible manufacturing strategies in machine tool component enterprises, and after developing an interview outline for the research questions, the content was redefined after discussion with experts and adjustments to the questions. During the interview, appropriate adjustment on the question was made according to the interviewee's answers, so that the results of the interview could be more closely matched to the real needs of the research and the most appropriate proposition.

The following questions are asked:

1. Interviewee: Executive Vice President

[1] What do you think are the benefits of using a flexible manufacturing system in the company's overall production, in terms of people, machines, materials and methods?

[2] How does the company's lean production management affect the current competitive market?

[3] How does the company's current use of IIoT in production help the business in the long run?

[4] What is your opinion on the opportunities of the company's operation transformation by investing a lot of labor, financial and material resources with the coming of Industry 4.0 smart manufacturing?

[5] What is your future business strategy for the introduction of smart manufacturing, given that you have a noble mission - small parts make a big world?

[6] What's your opinion on the company's decision to transform from a traditional OEM company to one of the leading precision manufacturing companies with high-end technology through the investment in IIoT and Smart Manufacturing?

[7] As the COVID-19 pandemic has not slowed down and stabilized, how has the introduction of advanced technologies related to flexible manufacturing, such as the IIoT and Smart Manufacturing, significantly changed your business strategy in response to the pandemic?

[8] What are your hopes and suggestions for the company's business strategy planning in the medium and long-term production? And any other information?

2. Interviewee: Manager, Production and Management Department

[1] What do you think are the benefits of using a flexible manufacturing system in the company's overall production, in terms of people, machines, materials and methods?

[2] How does the company's lean production management affect the current competitive market?

[3] How does the company's current use of IIoT in production help the business in the long run?

[4] What is your opinion on the opportunities of the company's operation transformation by investing a lot of labor, financial and material resources with the coming of Industry 4.0 smart manufacturing?

[5] What is your future business strategy for the introduction of smart manufacturing, given that you have a noble mission - small parts make a big world?

[6] What's your opinion on the company's decision to transform from a traditional OEM company to one of the leading precision manufacturing companies with high-end technology through the investment in IIoT and Smart Manufacturing?

[7] As the COVID-19 pandemic has not slowed down and stabilized, how has the introduction of advanced technologies related to flexible manufacturing, such as the IIoT and Smart Manufacturing, significantly changed your business strategy in response to the pandemic?

[8] What are your hopes and suggestions for the company's business strategy planning in the medium and long-term production and management? And any other information?

3. Interviewee: Manager, Processing Department 
[1] What do you think are the benefits of using a flexible manufacturing system in the company's overall production, in terms of people, machines, materials and methods?

[2] How does the company's use of IIoT in production facilitate site management?

[3] As a site manager, do you think the introduction of Smart Manufacturing has any direct or indirect benefits on the overall production line in terms of productivity, activation, customer delivery, and product quality?

[4] How does the company's lean production management affect the current competitive market?

[5] What major impact on the traditional technique workers do you think there will be due to the upgrade and transformation of the company's production by introducing advanced technology or equipment related to Industry 4.0 ?

[6] Given that you have a noble mission - small parts make a big world, do employees engaged in on-site production have the same lofty mission?

[7] What are your hopes and suggestions for the company's business strategy planning in the medium and long-term production? And any other information?

\subsection{Data Collection and Analysis}

This study was conducted by developing an interview outline, converting the audio files into verbatim transcripts, compiling the notes and summaries according to the individual interviews, and correcting and adjusting the relevant key records for the analysis. Under the qualitative research, the interview information and documents were first compiled and typeset sequentially before being analyzed, then the key statements were made, analyzed and categorized, and finally, the data were validated to ensure that the same statement of events was consistent to achieve the best possible truth and consistency. The data obtained from this study were summarized and analyzed in accordance with the following steps to obtain the analysis results. (1) Transcripts: The transcripts were transcribed from the audio files of the interviews, and the interviewees were represented in the alphabet. (2) Writing a summary of the key points and coding them appropriately: the questions in the outline were compiled and recorded in detail by writing an in-depth summary of the key points and the relevant discussions with the interviewees. The key elements of the interview and the related documents and materials were categorized, i.e., the verbatim text of the interviewees was carefully studied, and each sentence and paragraph were broken down and conceptually coded and translated. (3) In line with the research purpose, this study was able to identify and explore the factors that led to the introduction of a flexible manufacturing strategy for machine tool component enterprises, and to categorize and collate the key data from the interviewees through literature and actual interviews. The key elements of the verbatim transcripts were reviewed and retrieved to identify, categorize and code the key interrelated components and to develop the major propositions of this study. (4) The final step was to compile and summarize all the relevant data, thus combining the interview data with the main factors that led to a flexible manufacturing strategy model for tool and machine component manufacturers, and then presenting the conclusions and suggestions based on the findings of the cross-referencing study.

\section{Interview Results}

\subsection{Operation Model of the Company}

For more than 30 years, the case company has specialized in the manufacture of precision bearing nuts which are the indispensable components for machine tools and related high-end equipment, such as the application in ball screws and major spindles. In the process of expanding the global market, the case company is acutely aware of the high standard of quality demanded by its customers, which is different from the traditional nut industry, and the importance of high product quality is even higher than price. To meet the high-quality requirements of its international customers, the case company has invested in a large number of high-quality measuring equipment and has trained many professional quality control technicians, In addition, to acquire customers' trust in the measurement data provided to enhance its credibility, the case company has set up a laboratory for quality measurement and force calibration accredited by Taiwan Accreditation Foundation (TAF), in the hope that the measurement data can be internationally accredited and trusted by customers. With the changes in the market and the manufacturing model, the case company chose the difficult path of manufacturing transformation again in 2016 and was planning a strategy in line with the tailor-made smart manufacturing blueprint. The case company has invested heavily in smart manufacturing. For the case company, it is clear that professionalism is the basis for competition, and it knows that the future industrial structure will change significantly with its experience of 10 years. With the rapid establishment of complex equipment and automated production lines, it is imperative to make necessary adjustments to the previous mass production, because mass production is no longer an inevitable direction and it is time to think about how to adapt production modes to meet customer needs. For example, it is necessary to leverage complex production mode to shorten the time required for each 
production process and transport and change molds in the process through a production schedule, thus reducing the cost of unnecessary movements and time wastage of changing molds on the cage machine and repeating changing molds on the cage machine in the process of mass production. Therefore, in the whole production process, we have to think about how to integrate the production units and market positioning according to each customer's product, and how to leverage the whole process design process to quickly change molds to achieve the same efficiency of mass production, and to allow us to timely conduct inserting order production while receiving small-volume and large-variety orders. This enables the case company to maintain the same competitiveness when it comes to single-volume production with stable profitability, or when it comes to smallvolume and large-variety and high-value-added product production. Because of its product application fields and flexible layout of the market, the case company's production environment is a key factor in its development of flexible smart manufacturing. The market share of the case company's products in Taiwan is nearly $80 \%$, and the market share in Mainland China is more than $50--60 \%$, therefore, to balance the need for small-volume and large-variety and high precision with quantifiable manufacturing costs, the case company decides to invest in flexible intelligence to create this important manufacturing engineering.

Smart manufacturing is not an easy task. Moreover, the investment in smart manufacturing is not just about hardware, but also about the integration of different professional applications, such as MES, ERP, PDM and CRM systems. In the whole process of information system integration, the stable mutual operation of software and hardware, the analysis of data, and even the development and appropriate use of expert systems are all very important, as well as the training of maintenance operators and the analysis of professional data. When we can obtain relevant data but are not able to convert it into necessary information, the provision of such information becomes an unnecessary and heavy burden for managers at all levels. In a society where everything is connected, the failure of any one of the hardware or software applications to function properly will inevitably lead to business failure. Therefore, it is necessary to make overall planning before investing in smart manufacturing. As a small and medium-sized enterprise, the case company invested technicians and capital step by step according to its development needs. For example, in the early development stage of introduction, the case company was the first small and medium-sized enterprise in Taiwan to connect different brands and generations of old and new tools through the Internet. By visualization, it was easier to understand the relevant production information to provide managers as the basis for decision making, to optimize the equipment's activation. Today, the case company has invested a lot of professional manpower, necessary material and important resources, and has received excellent returns. Therefore, from the customer's inquiry and quotation to the completion of the entire order delivery, relying on the integration of systems, all the colleagues of the case company can know the current status of the customer's order through the ERP resource system, such as the procedure information in the product production process or the product packaging process. Furthermore, the managers can more quickly analyze and summarize the data in real-time and make the result obtained the basis for management decisions.

\subsection{Critical Success Factors for Case Interviews}

Results of the interviews compiled by this study are as follows:

1. The production model of the case company after receiving the order is a mixed production line with the single mass production and the small-volume and large-variety production, which undoubtedly adds a lot of difficulties in the production schedule. Therefore, the case company has developed a production model that divides the production units according to the customers' attributes and the market, which not only can reduce the waiting time of personnel and machines caused by frequent material transfer when conducting small-volume and large-variety production, but also can reduce the trouble of constantly recalibrating the machine to reach the capacity and quantity when conducting single mass production. With the complex machine equipment, it is possible to achieve quick mold changeover while running under the previous process design. In this way, the tool changeover time can be effectively shortened for all products of the same size and material. The site management only needs to transfer the pre-designed program files into the system and conduct the TMS tool management, and after arranging the appropriate setting time and program, the pre-production preparation can be completed with only technicians responsible for case machine operation on site.

2. For the case company, it is not necessary to implement lean management that the industry has been promoting in the early years. The basic spirit of lean management is to reduce inventory and waste. At the present stage of industry development, the demand for high-precision, small-volume and large-variety production is increasing, so if it rashly implements lean management and considers zero inventory, relatively speaking, it may incur more costs in production, such as calibration, measurement and material transportation costs. In conclusion, although lean management is important, it must be combined with 
information technology, digitalization and big data analysis to find the best way to improve efficiency and minimize the impact of material shortages.

3. In the past two to three years, whether it is because of the significant impact of the US-China trade or COVID-19 pandemic on global trade, the supply chain around the world has had to undergo appropriate changes. Thus, with the change of the supply chain, many international manufacturers have found deeprooted suppliers in Taiwan, which have excellent quality and profound strength. Although the case company has not developed the international market until the last few years, it has been aware of it even more deeply in recent years. The prerequisite for international manufacturers to agree to cooperate is that the partner company itself can really control the product quality well, and only then the price and delivery conditions. In addition, they attach importance to quality management, not only the necessary construction of high-end measurement equipment but also the cultivation and education of professional quality assurance personnel. In addition to the exclusive precision nut testing and precision measurement laboratory (TAF2867) accredited by Taiwan Accreditation Foundation (TAF). In recent years, the case company has further standardized and integrated the quality management system, in terms of standardization of measuring techniques for technicians, regular calibration of equipment, training of personnel, etc. Moreover, to integrate the information of measuring tools more effectively to enable them to analyze and integrate the information of the case company's core system, and to provide more accurate and timely information to managers for decision making in terms of the process planning of R\&D units, the processing technology of site units, and supply chain management integration of suppliers, the case company has introduced a quality data management system (Measurelink), which provides management with information for decision making. In order to realize the smart manufacturing system, the case company has started to build a smart factory with fewer people in 2018 and expects to open it fully in 2021. The management hopes to build production units through 24/6 human-machine collaboration, which makes the production mode more stable and improves the production efficiency to meet the customer's demand for just-in-time orders.

4. Specifically, if an enterprise wants to promote new directions and goals, in addition to investment in existing software and hardware equipment, it is more important for employees to be cohesive to the enterprise and for departments to cooperate. All employees at the case company are well aware of their mission, the differentiation in the competitive market, and the strategy for future development. Therefore, not only the operator's own pace must be fast but steady, but also all the case company's middle and senior management staff must be up to date with the changes in the market, must be in line with the case company's pace to work hard together in a new direction, which is also one of the key factors to its business success.

\subsection{Impact of COVID-19 Pandemic on the Development of the Case Company's Business Strategy}

Based on the results of the interviews, this study concludes as follows. The COVID-19 pandemic is having a dramatic and great impact on a global production model and the business model of the market, especially concerning the proximity of people to each other. If the U.S.-China trade war has contributed to the divergence of global supply chains, then the COVID-19 pandemic was accelerating the restructuring of global supply chains. As a result of the imbalance between supply and demand, many companies either had excessive inventory or had no inventory for being afraid of high inventory costs. After the COVID-19 outbreak began to slow down in the fourth quarter of 2020, the demand for customer orders suddenly grew dramatically. However, the companies were faced with many problems such as raw material inflation, the uncertainty of delivery, competition of exchange rate and shipping, including future labor costs. How to convince customers of the case company's ability to provide high quality, on-time delivery and reasonable prices through the entire production process becomes very important.

Because of the COVID-19 pandemic, different office models have been developed around the world, such as $\mathrm{SOHO}$ or shifts at different times, and customer visits have been changed to video conferencing. Although the case company does not have a regular need to visit customers, it regularly participates in major international exhibitions every year to discuss and introduce products directly to customers face to face. In the past two years, due to the COVID-19 pandemic, most of the major international exhibitions have been canceled, so the face-toface mode has been changed to video conferencing, in addition to the existing emails, which certainly have an impact on the speed of the case company's business development. There is still a difference in the overall effectiveness of the orders despite the friendship with customers. The following are the matters that affect the case company due to the pandemic:

1. Change of customer order pattern: Because of the uncertainty of market information, customers have lost 
their standard of order forecasting, so the rush orders have increased. The normal delivery time of 30 days is now often compressed to $15-20$ days, and the on-time delivery rate to customers is not only a test of the factory's response-ability but also of the coordination with third parties under full load, which is a very different challenge.

2. Price increase of raw materials: At present, prices of iron, pulp, wood and copper pellets are all increasing and even not available in the market, thus affecting product prices and delivery times. In anticipation of this market situation, the operators of the case company have purchased some demanded materials in advance to mitigate the severe impact on the customer side. Compared with the industry's unanimous increase, the case company recently began to adjust prices in response to the shortage of supply in the market.

3. U.S. Bail-out Policy: In the financial policies, the U.S. has monetary easing to stimulate the market, which has resulted in the continuous appreciation of the New Taiwan dollar and has led to exchange rate losses for those trading in the U.S. dollar, and may cause inflation in the future.

4. Explosive demand in Mainland China: After the COVID-19 pandemic has gradually alleviated, Mainland China has invested a lot in the construction of infrastructure, such as the installation of $5 \mathrm{G}$ base stations. The demand for construction requires more tooling equipment, which generates more demand for components. These orders not only require short delivery times, but may take up more than $70 \%$ of the case company's production capacity, so it is very important to make decisions about the delivery times of the customer base and to negotiate between the business side and the customer.

5. Customer development: In the past, the business model may focus on participating in major international trade exhibitions to conduct face-to-face conversations with potential customers to create business opportunities, but now it can only participate in online business exhibitions or use unfamiliar emails to visit and find potential customers, which greatly reduces the success rate of customer acquisition for the case company, but this situation can only be improved after the pandemic alleviation.

In terms of the overall operation of the case company, as the global COVID-19 pandemic has gradually stabilized, this year's order intake ratio is up more than 50\% compared to the same period last year in the recovery process of the global investment environment and the consumer market. The market shrinkage faced by the case company in the past two years and this year's recovery of the urgent demand is very different. It is very important to build a flexible and efficient smart manufacturing system within the case company. Many companies, whether investing at home or abroad, must be very clear about the need to obtain and grasp market information quickly, and in the whole production process, how to collect relevant information effectively and make decisions quickly to make the production of the case company more flexible and competitive becomes a significant topic.

\section{Discussion and Conclusions}

\subsection{Research Findings and Conclusions}

Every industrial revolution brings about a great change in human life. The new era of technological progress is witnessing a new industrial challenge, and the high-technology industries and machinery and equipment-related sectors bear the brunt of the industrial revolution. Smart manufacturing aims to enable enterprises in the face of market demands and rapid structural changes in the industry, to use the big data collected through the integration of machine networks and other relevant professional systems, to compile and analyze it into important information that can be provided to managers for decision making, and to accurately control all professional equipment and a series of production procedures more precisely, as well as reducing defect rates, productionrelated costs and shortening delivery times.

Smart manufacturing can be seen as an important business strategy that can respond to the transformation of market demands and production models, as well as the severe shortage of talents due to the younger-age trend. Therefore, the introduction of smart manufacturing may be the solution to the serious shortage problems for enterprises. Relatively speaking, it is not suitable for every enterprise, and it depends on the attributes of the relevant products and the strategic objectives of the enterprise. The costs associated with investing in smart manufacturing technologies, whether software, hardware, tangible or intangible, are enormous. Therefore, it is very important to make a comprehensive plan before investing in the technology, and if necessary, it should be combined with the advice of experts, so that the enterprise can implement the appropriate smart manufacturing technology step by step according to the plan developed. In addition, the selection and training of the relevant professionals employed by the case company are also very important, otherwise, the data analysis and decision making of the converted information will not be beneficial to the case company. The most important thing is the 
business philosophy of the operator, and only with the firm philosophy of the operator and the cooperation of the employees can the most suitable smart manufacturing strategy be developed.

\subsection{Suggestions}

In Taiwan's booming economy, the precision component manufacturing industry has played a pivotal role, not only as a source of foreign exchange but also as the rock upon which economic miracles are created. In recent years, the market trend in the precision component manufacture for production machine tools has shifted from sellers to buyers, and the government has recently been promoting the policy of Industry 4.0. Because of this, how to continue the fierce external competition in the industry and the development of new services related to smart manufacturing has become a hot topic in the precision component manufacturing industry. In particular, in the production tool and precision component industry, which is highly dependent on the sale of products, it is important to create more differentiated competition through service innovation to increase the added value of products under the standardized production procedure. Through the analysis of the in-depth interviews conducted by the experts in this study, four trends in the development of new services for smart manufacturing created in Taiwan have been identified:

1. The introduction of new service development in smart manufacturing has changed from the "option" to the "trend" for the precision component manufacturing industry of Taiwan's production machine tools. Because of the quick and dramatic change of market and customer demands, in addition to providing quality products, the precision component industry must also take into account market trends and the potential needs of customers, and thus develop service standards and provide the necessary professional services to market customers.

2. The development of new services for smart manufacturing has been transformed from "the provision of relevant assistance beyond products under the requirements of customers" to "the relevant ability to provide assistance beyond products in response to the requirements of customers". The establishment of this ability requires the necessary improvement of the internal nature of the company, including the "improvement of services", the "continuous extension of customer service lines", the "innovation of the company's services concerning existing services" and the "significant innovation of professional products". These four aspects can also be important steps for the development of smart manufacturing.

3. The lean production model must be integrated with the relevant supply chain upstream, midstream and downstream. However, small-scale suppliers are often unwilling or unable to cooperate, resulting in the whole production and supply chain being stagnant or inefficient. The government must appoint a counseling unit to provide comprehensive help through the industry-government-university model, not only in terms of skills but also in terms of concepts and intentions.

4. Taiwan's manufacturing industry is export-oriented, and the exchange rate policy and cross-strait relations have a great impact on the market competitiveness of Taiwan's machine tool component manufacturing industry. It is hoped that the government can consider the industry's position in-depth, as the industry can survive so that people can live and work in peace and contentment, and that the relevant government departments can take the viewpoint of the enterprises to influence the development behaviors or policies of the entire industry.

\section{Acknowledgement}

This research is supported by the National Chin-Yi University of Technology, Taiwan, R.O.C. (under Project:

Discussion on Integrating Industry Experts' Collaborative Teaching, Institutional Visits, and Issue method to Improve Student Learning Outcomes.)

\section{References}

Bartodziej, C. (2017). The concept industry 4.0: An empirical analysis of technologies and applications in production logistics. Wiesbaden: Springer Fachmedien Wiesbaden. https://doi.org/10.1007/978-3-658-16502-4

Benbasat, I., Goldstein, D., \& Mead, M. (1987). The Case Research Strategy in Studies of Information Systems. MIS Quarterly, 11(3), 369-386. https://doi.org/10.2307/248684

Cooper, M. (1995). Drinking to regulate positive and negative emotions: A motivational model of alcohol use. Journal of personality and social psychology, 69(5), 990-1005. https://doi.org/10.1037//0022-3514.69.5.990

D'Souza, D. \& Williams, F. (2000). Toward a taxonomy of manufacturing flexibility dimensions. Journal of Operations Management, 18(5), 577-593. https://doi.org/10.1016/S0272-6963(00)00036-X 
Dyer, W. G., \& Sánchez, M. (1998). Current state of family business theory and practice as reflected in family business review 1988-1997. Family Business Review, 11(4), 287-295. https://doi.org/10.1111/j.17416248.1998.00287.x

Feld, W. (2001). Lean manufacturing: Tools, techniques, and how to use them. FL.: St. Lucie Press.

Gerwin, D. (1993). Manufacturing flexibility: A strategic perspective. Management Science, 39(4), 395-410. https://doi.org/10.1287/mnsc.39.4.395

Groover, M. (2001). Automation, production systems and computer-integrated manufacturing. Upper Saddle River, NJ: Prentice Hall.

Inman, R. (1991). Flexible manufacturing systems: Issues and implementation. Industrial Management, 31(4), 711.

Krafcik, J. (1988). Triumph of the lean production system. Sloan Management Review, 30, 41-52.

Lai, W. (2017). Early warning of equipment failure: Reduce downtime losses. Industrial Technology, 312, 34-35.

Lau, R. (1999). Critical factors for achieving manufacturing flexibility. International. Journal of Operations \& Production Management, 19(3), 328-41. https://doi.org/10.1108/01443579910249741

Lee, C. (2017). The application of lean production way into various and small amount production enterprises. Journal of Global Business Operation and Management, 9, 143-160. https://doi.org/10.29967/JGBOM

Luggen, W. (1991). Flexible manufacturing cells and systems. Englewood Cliffs, NJ: Prentice Hall.

Maleki, R. (1991). Flexible manufacturing systems: The technology and management. Englewood Cliffs, NJ: Prentice Hall.

Oke, A. (2005). A framework for analyzing manufacturing flexibility. International Journal of Operations \& Production Management, 25(10), 973-996. https://doi.org/10.1108/01443570510619482

Pan, S. (2003). Qualitative research-Theory and application. Taipei: Psychological Publishing Co., Ltd.

Ramadan, M. \& Salah, B. (2019). Smart lean manufacturing in the context of Industry 4.0: A case study. International Journal of Industrial and Manufacturing Engineering, 13(3), 174-181. https://doi.org/10.5281/zenodo.2643523

Rüßmann, M., Lorenz, M., Gerbert, P., Waldner, M., Justus, J., Engel, P., \& Harnisch, M. (2016). Industry4.0Future of Productivity. Boston Consulting Group (BCG). Retrieved from https://imagesrc.bcg.com/Images/BCG_Industry_40_Future_of_Productivity_May_2016_CHN_tcm9-127482.pdf

Wang, Y., Chen, T., Chiang, H. \& Pan, H. (2016). A simulation analysis of part launching and order collection decisions for a flexible manufacturing system. Simulation Modelling Practice and Theory, 69, 80-91. https://doi.org/10.1016/j.simpat.2016.09.006

Wen, C., \& Yang, K. (2000). Interview survey method. Taipei: Tung Hua Book Co., Ltd.

Womack, J., \& Jones, D. (2003). Lean thinking. NY: Free Press.

Wong, S., Mak, K., \& Lau, H. (1999). An object-oriented model for the specification of manufacturing systems. Computers and Industrial Engineering, 36(3), 655-671. https://doi.org/10.1016/S0360-8352(99)00157-6

$\mathrm{Wu}, \mathrm{T}$. (2019). AIoT for Smart Manufacturing. Journal of Petroleum, 55(4), 71-78. https://doi.org/10.30128/JP

Wu, W. (2015). Business research methods. Taipei: Hwa Tai Publishing Co.

Yin, R. (2009). Case study research: Design and methods (4th ed.). Thousand Oaks, CA: Sage.

\section{Copyrights}

Copyright for this article is retained by the author(s), with first publication rights granted to the journal.

This is an open-access article distributed under the terms and conditions of the Creative Commons Attribution license (http://creativecommons.org/licenses/by/4.0/). 